\title{
Definition of a labelling code for the noise emitted by machines
}

\author{
Marcos D. Fernandez, Manuel Recuero , Jose M. Blas \\ Escuela Universitaria Politecnica de Cuenca, Universidad de Castilla-La Mancha, Campus Universitario, I607I Cuenca, Spain \\ GI2A2, Universidad Politecnica de Madrid, Ctra. Valencia km 7, 28031 Madrid, Spain
}

\begin{abstract}
It has been increasingly realised that traditional parameters, such as A-weighted sound levels, sound power and noise spectra in octaves or third octaves are not enough to describe a sound and that machine labels should show more subjective information about the emitted noise. A new labelling system based on empirical data is proposed. The methodology of the study used as the basis for the proposal is explained, as well as the objective and subjective characteristics to be included in the new label. The uses and applications of the label are discussed briefly.
\end{abstract}

Keywords: Noise; Machinery; Labelling; Acoustic power; Sound quality

\section{Introduction}

In the Directive $96 / 61 / \mathrm{CE}$, the European Union states that noise as a contaminant agent needs to be decreased; in addition the European Parliament and the Council about the Evaluation and Management of the Environmental Noise state in the Directive 2003/49/CE the general commitments for taking preventive measures against industrial noise's pollution, particularly, employing better technical solutions, and for its effective application before 2007 through a license system to set the noise emission limit or equivalent technical solutions in each place.

The directive $89 / 392 / \mathrm{CE}$, commonly known as the "European Directive for Machines" and its updates in the new directive 98/37/CE [1], already include settings about health and safety related to the design and making of machines and their noise. These directives state that the machines should be designed and manufactured so as to produce minimum noise risks, taking into account the technical progress and the means available to reduce the noise, specially at source. Furthermore, it also sets the requirement of the "CE" label for all the machines as a certificate of accomplishing the European directives and it enforces to display the A-weighted sound level clearly and, in some cases, the A-weighted sound power level as well.

The manufacturers of industrial machinery give scarce, or even no information about the acoustics of their products due to the absence of updated norms and regulation about certain aspects. However, the noise emitted by those machines is an important aspect; it may cause exhaustion (with the consequent productivity reduction), lapses of concentration or stress (causing working accidents), severe physiological lesions like progressive loss of hearing, or even deafness. Statistics say that approximately $28 \%$ of sick leaves are directly or indirectly due to noise.

Nowadays, it is difficult for the production process to take into account this kind of information, as there are no industrial simulation tools which are able to include real models of sound sources measured according to the standards. As a consequence, the problem must be analysed afterwards, testing that noise in the workplace is not over the allowed thresholds. This is not the optimum solution and it would be much better to design the machine from the beginning taking into account the acoustics to avoid any harm or annoyance from the noise emitted. 
Manufacturers really give importance to sound perception and, although they do not know about the psychoacoustic parameters or their measurement and use, they would include sound quality techniques in their products' design if there was an easy method since all of them agree that the $\mathrm{dB}$ scale is difficult to understand, as it is confirmed by the I-INCE questionnaire

Then, the characterization of machines with both, newer and classical parameters, would mean an important advancement. For that reason, sound quality measurements must be considered, since psychoacoustic parameters can relate the noise emitted by the machines with its annoyance and the risk of hearing loss.

Sound quality is a recent technique, already tested for car design, that tries to describe the product sound taking users' sensations as a basis; these sensations have two parts: an objective one to extract the psychoacoustic parameters, and a subjective one to valuate the answers of the users to a survey

Joining the objective and subjective characterizations, patterns can be defined for each type of machine to extract common characteristics.

Those patterns may be useful to catalogue the machines including subjective parameters, as pleasantness or annoyance. With those parameters and the classical ones, an alternative labelling code, which would include objective and subjective characteristics of a machine and which would display the degree of risk of noise exposure, can be defined.

Labelling must be easy to understand, based on reproducible test methods and taking the A-weighted sound power as the basic level Sound quality of a product is multidimensional and then, together with the $\mathrm{A}$-weighted sound power, some other main, but easily understandable, objective and subjective magnitudes must be shown. To get it, several options can be considered: coloured labels, welldefined and closed numeric scales, and quality marks to guarantee defined norms, as for instance, the European Ecolabel the German Blue Angel and the Nordic "Swann" Regarding this point, both manufacturers and consumers agree that labelling may be very useful to inform about the emitted noise, but they also agree about the uncertainty the multiple labelling systems could mean for different countries

The proposal of this paper is to define a new labelling system based on empirical data to characterize the noise emitted by the machines. The methodology of the study will also be explained, as well as the objective and subjective characteristics to be included in the new label. In addition, the building up of the label and, finally, a brief discussion about its uses and applications are also introduced.

\section{Methodology of the study}

Based on the study of "sound quality assessment in the UK industries" presented in 2004 it can be stated that two given machines can have the same A-weighted sound power level but sound different, and besides, that the man- ufacturers would include information about the sound quality of their products, then the proposed labelling must cover, at least, these two aspects: sound power and sound quality.

That is the reason why we have carried out a study with machines used by workers to derive a new labelling system. Our study has taken an initial set of machine families to be analysed, which will be widened to corroborate the results. The machines are: drills, grinders, generating sets and panel saws.

The classical parameters to be determined for each machine are: global A-weighted sound power level, power and sound pressure levels in octaves or third octaves. All the measures will follow standard norms, specially ISO 3744 and ISO 9614-2 that take the sound power from sound pressure or intensity, respectively.

To study the sound quality, binaural recordings will be taken for each machine in the workplace with a head and torse simulator (HATS). Objective psychoacoustic parameters, like loudness, sharpness, roughness and fluctuation strength can be derived by processing these recordings. Correlations can be established with the objective classical parameters, the maximum sound exposure time, the risk of hearing loss and the most appropriate hearing devices

Subjective part of the sound quality is established through a set of surveys to a representative sample of people (at least 16 for each evaluated machine) that listen to the binaural recordings Those data allow to derive statistics and to establish correlations with classical and sound quality parameters.

\section{Objective part}

A-weighted sound power level is the acoustic parameter that characterizes a machine by its own, as it does depend, essentially, on the own machine. Besides, this is the parameter chosen by European directives to follow the CE mark. Therefore, this must appear in the new labelling code.

From another point of view, and following the European directive 2003/10/CE the other regulated aspect is the noise perceived at the workplace. Then, it can be stated that if the equivalent noise level for the whole working day at the workplace is less than $80 \mathrm{dBA}$, there will be no risk; if it is between 80 and $85 \mathrm{dBA}$, workers must be informed, they should have quinquennial checkups and they should be given hearing devices if they wish; if the level is between 85 and $90 \mathrm{dBA}$, workers should have triannual checkups and must be given hearing devices; and if the level is higher than $90 \mathrm{dBA}$, a technical solution for those emissions must be applied, and if it is not possible, annual checkups must be done and hearing devices must be used.

Accordingly, the A-weighted sound pressure level $\left(L_{\mathrm{p}_{\mathrm{A}}}\right)$ is chosen as if it were perceived equivalently in the whole working day, that is, as if the worker were continuously using this machine for the $8 \mathrm{~h}$ of the working day.

To make this code more outstanding, coloured labels are being used with colours of the traffic light, so, by just seeing 
the colour one can know the acoustic risky index of the machine

Then, the following is suggested:

- If $L_{\mathrm{p}_{\mathrm{A}}} \leqslant 80 \mathrm{dBA} \Rightarrow$ no risk $\Rightarrow$ GREEN

- If $80<L_{\mathrm{p}_{\mathrm{A}}} \leqslant 85 \mathrm{dBA} \Rightarrow$ low risk $\Rightarrow$ YELLOW

- If $85<L_{\mathrm{p}_{\mathrm{A}}} \leqslant 90 \mathrm{dBA} \Rightarrow$ medium risk $\Rightarrow$ ORANGE

- If $L_{\mathrm{p}_{\mathrm{A}}} \geqslant 90 \mathrm{dBA} \Rightarrow$ high risk $\Rightarrow$ RED

These colours have been chosen considering people's psychological reaction to them green gives security, yellow indicates activity, orange causes restlessness and fear, while red evoques danger and excitement.
Therefore, A-weighted sound power level and colours' risk-guide are chosen as the objective parameters that best describe a machine acoustically.

Fig. 1 shows all the values and codes proposed for the complete measured families.

\section{Subjective part}

Regulations or international standards are not available yet for sound quality. Then, there are no clear indications as in the objective part.

Psychoacoustic parameters defined by Zwicker have been chosen for the objective part of the sound quality. In

\begin{tabular}{|c|c|c|c|c|c|c|c|c|c|c|c|c|}
\hline MACHINE & $\begin{array}{l}\text { LwA } \\
\text { (dBA) }\end{array}$ & $\begin{array}{l}\text { LpA } \\
\text { (dBA) }\end{array}$ & $\begin{array}{c}\mathrm{L} \\
\text { (son) }\end{array}$ & $\begin{array}{c}\mathrm{S} \\
\text { (acum) }\end{array}$ & $\begin{array}{c}\mathrm{R} \\
\text { (asper) }\end{array}$ & $\begin{array}{c}\mathrm{F} \\
\text { (vacil) }\end{array}$ & $\overline{\text { OPA }^{\prime}}$ & Q9 & Q10 & $\overline{\mathrm{PA}}$ & OBJ. C. & JBJ.C. \\
\hline \multicolumn{13}{|l|}{ Grinders } \\
\hline Casals AG21 & 100,8 & 95,5 & 226 & 3,14 & 0,51 & 1 & 127 & 4 & 3,1 & 7 & 100,8 & 7 \\
\hline Casals AG6-115 & 95,4 & 87,4 & 75,1 & 3,09 & 0,62 & 1,19 & 110 & 2,4 & 4,7 & 4 & 95,4 & 4 \\
\hline Milwakee AG8-115Q & 97,9 & 94,2 & 109 & 3,07 & 0,47 & 0,89 & 116 & 3 & 3,9 & 6 & 97,9 & 6 \\
\hline Casals DL178 & 100,3 & 92,3 & 115 & 2,8 & 0,52 & 1 & 115 & 3,3 & 3 & 6 & 100,3 & 6 \\
\hline LG G705 & 95,5 & 87,5 & 80,2 & 2,96 & 0,51 & 1,08 & 111 & 4,3 & 3,7 & 7 & 95,5 & 7 \\
\hline Bosch GWS 6-115 & 94 & 89,9 & 81,9 & 2,94 & 0,51 & 0,95 & 111 & 3,7 & 4 & 6 & 94 & 6 \\
\hline Bosch GWS 7-115 & 96,2 & 92,6 & 86,4 & 2,87 & 0,45 & 0,85 & 111 & 4,1 & 3,5 & 7 & 96,2 & 7 \\
\hline Bosch PWS 600 & 99,7 & 91,8 & 94,3 & 3,53 & 0,54 & 0,98 & 115 & 3 & 3,1 & 6 & 99,7 & 6 \\
\hline Metabo W7-115 & 93,5 & 85,5 & 89,3 & 2,9 & 0,48 & 1,04 & 112 & 3,3 & 2,6 & 7 & 93,5 & 7 \\
\hline AEG WS $7-115 \mathrm{M}$ & 93,7 & 85,7 & 82,2 & 2,91 & 0,46 & 0,98 & 111 & 3,3 & 3,7 & 6 & 93,7 & 6 \\
\hline \multicolumn{13}{|l|}{ Panel Saws } \\
\hline Griggio CA400 & 82 & 78,9 & 31 & 2,13 & 0,49 & 1 & 95 & 3,7 & 3 & 7 & 82 & 7 \\
\hline Altendorf F45 & 89,2 & 85,5 & 89 & 2,64 & 0,43 & 0,86 & 111 & 3,2 & 2,4 & 7 & 89,2 & 7 \\
\hline Lazzari LOGO3200 & 98,7 & 95,6 & 67,3 & 2,43 & 0,52 & 1,1 & 106 & 3,7 & 3 & 7 & 98,7 & 7 \\
\hline Ortza OPAL32 & 90,6 & 86,9 & 44,5 & 2,26 & 0,55 & 1,02 & 100 & 3,8 & 2,1 & 7 & 90,6 & 7 \\
\hline Griggio SC32 & 83,8 & 82,2 & 49 & 1,81 & 0,45 & 0,83 & 100 & 3,8 & 3,5 & 7 & 83,8 & 7 \\
\hline Steton SC3200E & 84,1 & 80,7 & 36,4 & 1,95 & 0,5 & 0,92 & 96 & 3,1 & 4,4 & 5 & 84,1 & 5 \\
\hline SCM SI16WA & 91 & 80,9 & 38,1 & 2,09 & 0,48 & 0,98 & 97 & 3,7 & 2,7 & 7 & 91 & 7 \\
\hline Ortza SI370I & 91,3 & 86,4 & 44,2 & 2,67 & 0,51 & 1,45 & 101 & 3,6 & 1,9 & 7 & 91,3 & 7 \\
\hline Lazzari TEMA3000iS & 90,2 & 85,9 & 81,3 & 2,78 & 0,5 & 1,1 & 110 & 4,3 & 2,4 & 8 & 90,2 & 8 \\
\hline Robland Z320 & 85,7 & 83,7 & 50,1 & 1,85 & 0,41 & 0,95 & 100 & 3,4 & 2,9 & 7 & 85,7 & 7 \\
\hline \multicolumn{13}{|l|}{ Generating Sets } \\
\hline Grupodisa 1306-9TK & 86 & 74,7 & 49,9 & 1,5 & 0,47 & 0,81 & 100 & 2,9 & 3 & 6 & 86 & 6 \\
\hline Himoinsa 1500G & 87,6 & 81,6 & 33,1 & 2,42 & 0,48 & 1,46 & 97 & 4 & 3 & 7 & 87,6 & 7 \\
\hline Gesan DPS140 & 87,5 & 79,5 & 42,1 & 1,35 & 0,52 & 1,19 & 99 & 3,5 & 3,4 & 6 & 87,5 & 6 \\
\hline Himoinsa EST-INS & 87 & 79,6 & 54,4 & 1,65 & 0,51 & 1,17 & 102 & 3,8 & 2,8 & 7 & 87 & 7 \\
\hline Himoinsa EST-INS1500G & 87,5 & 80,8 & 38 & 1,22 & 0,5 & 0,9 & 97 & 3,1 & 4,5 & 5 & 87,5 & 5 \\
\hline Grupodisa HD434D1 & 95,8 & 84,5 & 66,8 & 1,47 & 0,49 & 0,93 & 104 & 3,2 & 3 & 6 & 95,8 & 6 \\
\hline Himoinsa HIW-200 & 87,4 & 80,4 & 49,2 & 1,5 & 0,55 & 1,16 & 101 & 3,2 & 3,3 & 6 & 87,4 & 6 \\
\hline Himoinsa MOV-INS32 & 80,3 & 74,8 & 28,5 & 1,24 & 0,52 & 0,86 & 93 & 3 & 3,8 & 6 & 80,3 & 6 \\
\hline Himoinsa MOV-INS80 & 85,5 & 78,4 & 50,8 & 1,75 & 0,5 & 1,12 & 101 & 3,5 & 2,6 & 7 & 85,5 & 7 \\
\hline F.G.Wilson P100 & 88,9 & 78,8 & 55,3 & 1,25 & 0,49 & 0,84 & 101 & 3,4 & 4,7 & 5 & 88,9 & 5 \\
\hline \multicolumn{13}{|l|}{ Drills } \\
\hline Skil 6365 & 93,2 & 85,2 & 66,1 & 2,77 & 0,51 & 1 & 107 & 3,4 & 1,6 & 7 & 93,2 & 7 \\
\hline Mannesman BM500 & 85,2 & 77,1 & 49,4 & 2,62 & 0,43 & 0,93 & 102 & 4,1 & 1,9 & 8 & 85,2 & 8 \\
\hline LG D913A & 91,2 & 83,2 & 92,9 & 3,3 & 0,48 & 1,05 & 114 & 4,4 & 2,2 & 8 & 91,2 & 8 \\
\hline Bosch GBH3-28FE & 98,4 & 90,4 & 128 & 2,91 & 0,49 & 0,98 & 117 & 3,9 & 3,1 & 7 & 98,4 & 7 \\
\hline Black\&Decker KD162 & 87 & 79 & 79,9 & 2,61 & 0,47 & 0,96 & 109 & 3,9 & 2,8 & 7 & 87 & 7 \\
\hline AEG PN3500X & 100,2 & 92,2 & 123 & 2,89 & 0,63 & 0,93 & 117 & 3,6 & 3 & 7 & 100,2 & 7 \\
\hline AEG PN4000E & 91,2 & 83,2 & 87,6 & 2,67 & 0,48 & 1,35 & 111 & 3,9 & 3,9 & 6 & 91,2 & 6 \\
\hline AEG SBE550R & 89 & 80,9 & 47,1 & 2,76 & 0,49 & 1,09 & 102 & 3,8 & 2,2 & 7 & 89 & 7 \\
\hline Skil hammer1750 & 95 & 87 & 85,1 & 2,33 & 0,47 & 0,97 & 109 & 4,5 & 1,6 & 9 & 95 & 9 \\
\hline Casals VT622 & 95,6 & 87,6 & 111 & 2,73 & 0,47 & 0,98 & 114 & 3,9 & 2,4 & 7 & 95,6 & 7 \\
\hline
\end{tabular}

Fig. 1. Labelling calculation for the measured machines. 
that reference, the author indicates how the sound quality can be evaluated with an unique value that joins the influence of loudness, sharpness, roughness and fluctuation strength. This is done through the psychoacoustic annoyance (PA), named here as objective psychoacoustic annoyance (OPA), and determined as Eq. (1) shows.

$$
\begin{aligned}
& \mathrm{OPA}=N_{5}\left(1+\sqrt{w_{\mathrm{S}}^{2}+w_{\mathrm{FR}}^{2}}\right) \\
& \left\{\begin{array}{lll}
w_{\mathrm{S}}=0.25(S-1.75) \log \left(N_{5}+10\right) & \text { if } & S>1.75 \\
w_{\mathrm{S}}=0 & \text { if } & S \leqslant 1.75
\end{array}\right. \\
& w_{\mathrm{FR}}=\frac{2.18}{N_{5}^{0.4}}(0.4 F+0.6 R)
\end{aligned}
$$

where $N_{5}$ is the percentile 5 of loudness - or peak value of loudness in son -, $S$ is sharpness in acum, $R$ is roughness in asper, and $F$ is fluctuation strength in vacil.

Eq. (1) is followed, but only approximating $N_{5}$ by $N, N_{5}$ - the peak value - by $N$ - the measured value of loudness, which is the available one.

As Fig. 1 shows in the OPA column, there is a great variety of values, that, together with the lack of indexes to value psychoacoustics, makes it very difficult to assess the obtained data.

Supposing one machine has only the loudness available, then the psychoacoustic annoyance will have exactly the same value. Then, that value could be changed into loudness level $L_{\mathrm{N}}$, in phon, with Eq. (2) and be compared to the equal loudness curves, where there are already some indexes to value.

$L_{\mathrm{N}}=\frac{10}{\log 2} \log N+40$

Applying this last supposition to the psychoacosutic annoyance, the psychoacustic annoyance level $\left(\mathrm{OPA}^{\prime}\right)$ - given by Eq. (3) - is obtained.

$\mathrm{OPA}^{\prime}=\frac{10}{\log 2} \log \mathrm{OPA}+40$

This value is considered as a loudness level to determine a scale of the psychoacoustic acceptance of a machine.

Hundred phons at $1 \mathrm{kHz}$ is the reference taken for the $\mathrm{C}$-weighting of high loudness levels. Here, the same reference is proposed, and any value higher than that level will be qualified as dangerous. Then, the following coloured classification is proposed to indicate quickly the annoyance degree:

- If $\mathrm{OPA}^{\prime} \leqslant 90 \Rightarrow$ very acceptable $\Rightarrow$ GREEN

- If $90<\mathrm{OPA}^{\prime} \leqslant 100 \Rightarrow$ acceptable $\Rightarrow$ YELLOW

- If $100<\mathrm{OPA}^{\prime} \leqslant 120 \Rightarrow$ annoying $\Rightarrow$ ORANGE

- If $\mathrm{OPA}^{\prime} \geqslant 120 \Rightarrow$ very annoying $\Rightarrow \mathrm{RED}$

For the subjective part of the sound quality there are two questions of the survey that may help to extract an indicator about the acceptance of a machine.
Those questions are numbers 9 and 10. Number 9 asks if the heard sound is "Pleasant", with 1 point, or "Unpleasant", with 5 points. Meanwhile, question 10 asks "How long, from a whole working day, would you be willing to use the machine that makes the noise you are hearing?", with free answer from 0 to $8 \mathrm{~h}$ non-stop in intervals of half an hour.

So, on the one hand, the global acceptance is valued in terms of pleasantness, and, on the other hand, the perceived time of use of a machine.

Then, an index of perceived subjective psychoacoustic annoyance (SPA) is proposed to weigh equally both aspects through a $1-10$ evaluating scale. The nearer the value is to 10 , the more annoying that machine will be, and the nearer to 1 , the less annoying it will be.

With this definition of SPA, its calculation is made with Eq. (4).

$\mathrm{SPA}=Q 9+\left(5-Q 10 \frac{5}{8}\right)$

In Eq. (4) both questions have the same importance, question 9 , with values from 1 to 5 directly, because its scale has the same meaning towards high values; while question 10 has a maximum value of 8 , so it has to be rescaled to 5 as the maximum and its scale inverted, because its meaning is the opposite of the annoyance scale.

Fig. 1 shows all the calculated values for the subjective labelling.

\section{Labelling}

Fig. 1 shows all the necessary values to build this alternative labelling code, as well as the codes obtained for each machine in the columns "OBJ-C" and "SUBJ-C" for the objective and subjective parts, respectively.

Labels obtained are coherent, as the colours for a machine are similar or close, that is, there is no machine qualified very well acoustically and very bad psychoacoustically, or the other way round.

The AG21 grinder should be remarked since it is considered as very risky for workers, with a sound power level of $100.8 \mathrm{dBA}$, and very annoying subjectively, with an index of 7 out of 10 .

No machine has been qualified subjectively as "very acceptable" (green colour ${ }^{1}$ ), which states once more the rejection of the machinery noise and corroborates the importance of considering the noise made at source to achieve a better acceptance.

Fig. 2 shows the label proposed for this coding. The box on the left has the letter " $\mathrm{O}$ ", from objective, on the corner, and the box on the right has the letter "S", from subjective.

The objective box is coloured according to the Aweighted sound pressure level and printed with a number 


\section{\begin{tabular}{|l|l|}
\hline 00,6 & s 7 \\
\hline
\end{tabular}}

Fig. 2. Example of label.

in the middle, rounded to one decimal, that is the Aweighted sound power level.

The subjective box is coloured according to the psychoacoustic annoyance given by the Zwicker parameters and printed with a number in the middle. That number, without decimals, is calculated from the psychoacoustic annoyance given by the answers to questions 9 and 10 of the survey to users.

So, with such a label one can quickly acquire a lot of information about a machine:

- A-weighted sound power level.

- Risk of sound exposure.

- Sound quality valuation.

- Annoyance for users.

Fig. 2 shows an example of labelling. This machine presents a medium risk of sound exposure, an emitted sound power level of $90.6 \mathrm{dBA}$, an objective psychoacoustic annoyance qualified as acceptable and a subjectively perceived annoyance of 7 out of 10 .

A machine will be better acoustically when both boxes are as near as possible to green colour and their numbers are as low as possible.

As an example, we take two machines as equally efficient, one labelled Orange-98.5, Yellow- 6 , and the other Yellow-99, Yellow-6. The second machine would be better, despite having a bit higher power, as its risk for workers is less, given that it has a yellow code, ${ }^{1}$ that is nearer to green than orange.

\section{Concluding remarks}

There has been introduced a labelling code, with the objective (acoustic) and subjective (psychoacoustic) parameters of a machine, which can be evaluated quickly and easily.

The code has two parts, the left one for the objective aspect and the right one for the subjective data. The objective part reports the A-weighted sound power level with its numerical value, and the risk of exposure time with a coloured scale, that, ordered from lower to higher risk, is green, yellow, orange and red.

The subjective part has information about the annoyance based on the objective psychoacoustic parameters of sound quality through a coloured scale, that ordered from lower to higher annoyance, is green, yellow, orange and red; and it also reports, numerically, the annoyance extracted from the answers to the psychoacoustic survey that asks about the pleasantness of the machine and the maximum time that users are willing to use it.

Application of this coding to all the measured machines reveals that there is no machine with optimum qualification in the subjective part, which indicates that the machinery design should be improved acoustically. Coherence between the objective and subjective qualifications is also remarkable, as they are quite similar, that is, there is no such machine very well considered objectively and very bad subjectively, and the other way round.

According to this acoustic labelling, the nearer a machine has green colours and the lower its numerical values are, the better it will be.

The utility of this code is quite obvious, given that many acoustic and psychoacoustic parameters of a machine can be known immediately. Its introduction might be rather troublesome, mainly for those manufacturers whose labels were negative in any aspect, as it could cause a fall in the sales. However, from another point of view, this must be a motivation to improve their products to obtain a positive acoustic assessment.

Examples of that motivation can be found in the technological industry, where there are great companies that already apply sound quality controls to their products. Generally, it does not mean that sound emission must be reduced, but that the emitted noise should be non-annoying and non-harmful

\section{Acknowledgement}

This article is included in the Project CCSAI (CICYT, Ref. DPI 2004-07073-C02-02).

\section{References}

Directive 98/37/EC of the European Union, Approximation of the Legislations of the State Members about Machines; 1998.

Maluski S, Churchill C, Cox TJ. The state of sound quality testing in the UK Industry. ICA-2004, Japan.

Berry BF. The work of I-INCE Technical Study Group 2 on noise labels for consumers and industrial products. In: Proceedings of Internoise 2002, USA; 2002.

Otto N, Amman S, Eaton C, Lake S. Guidelines for jury evaluations of automotive sounds, Sound and Vibration Control Magazine; April, 2001.

Porter ND, Berry BF. A study of standard methods for measuring the sound quality of industrial products. Final Report. NPL Report CIRA (EXT)021, January, 1997.

Regulation (EC) No 1980/2000. www.eco-label.com. www.blauer-engel.de.

www.svanen.nu.

Maluski S, Churchill C, Cox TJ. Sound quality testing and labelling of domestic appliances in the UK. In: Proceedings of Internoise 2004, Prague.

International Organization for Standardization ISO 3744. Determination of sound power levels of noise sources using sound pressure. Engineering method in an essentially free field over a reflecting plane; 1994.

International Organization for Standardization ISO 9614-2. Determination of sound power levels of noise sources using sound intensity. Part 2: Measurement by scanning; 1996.

Farina A, Ugolotti E. Subjective evaluation of the sound quality in cars by the auralisation technique, Pre-prints of the 103rd AES Convention, New York; September, 1997. 
Nordtest-Delta Report, Measurements and Judgments of Sound in relation to Human Sound Perception, no. AV 1461/01; 2001.

Directive 2003/10/EC of the European Union, Minimum disposures on safety and health related to the exposure of workers to the risks derived from physical agents (noise); 2003.
Cortes JM. Tecnicas de prevencion de riesgos laborales. Seguridad e higiene en el trabajo (Risks at work prevention techniques. Safety and health at work), Tebar, Madrid; 2003.

Zwicker E, Fastl H. Psychoacoustics. Facts and models. Berlin: Springer-Verlag Publ.; 1999.

www.silent.se. 